\title{
Proteomic identification of keratin alterations with enhanced proliferation of oral carcinoma cells by loss of mucosa-associated lymphoid tissue 1 expression
}

\author{
YUKIHIRO KAWAMOTO ${ }^{1}$, YOSHITO OHYAMA ${ }^{1}$, TADASHIGE CHIBA ${ }^{2}$, \\ HISAO YAGISHITA $^{3}$, HIDEAKI SAKASHITA ${ }^{1}$ and KAZUSHI IMAI ${ }^{2}$ \\ ${ }^{1}$ Division of Oral and Maxillofacial Surgery 2, Department of Diagnostic and Therapeutic Sciences, School of Dentistry, \\ Meikai University, Saitama; ${ }^{2}$ Department of Biochemistry, School of Life Dentistry at Tokyo, \\ ${ }^{3}$ The Nippon Dental University Hospital, The Nippon Dental University, Tokyo, Japan
}

Received April 16, 2013; Accepted May 15, 2013

DOI: 10.3892/ijo.2013.1990

\begin{abstract}
Progression of oral carcinomas associates with aberrant activation and inactivation of molecules that work in established or unknown pathways. Although mucosa-associated lymphoid tissue 1 (MALT1) expressed in normal oral epithelium is inactivated in the aggressive subset of carcinomas with worse prognosis, phenotypic changes of carcinoma cells upon the loss of expression is unknown. We performed a proteomic analysis to identify MALT1-regulated proteins in oral carcinoma cells. Four different keratins were included in the ten most abundantly changed proteins. K8/18 were upregulated in MALT1 stably-expressing carcinoma cells and K5/14 in MALT1-marginal control cells. K8/18 upregulation and K5/14 downregulation were MALT1 dose-dependent and observed in a series of oral carcinoma cells. MALT1 suppressed cell proliferation (0.52-fold, $\mathrm{P}<0.01)$ and its dominant-negative form stimulated it $(1.33$ fold, $\mathrm{P}<0.01)$. The decreased proliferation associated with reduction of cyclin D1, which was recovered by the short interfering RNA against MALT1. Taken together, loss of MALT1 expression alters keratin expression and enhances proliferation of carcinoma cells, and may progress oral carcinomas into the advanced state.
\end{abstract}

\section{Introduction}

Squamous cell carcinoma is a most common malignant neoplasm of the oral cavity and the patient prognosis is still worse than that of all other cancers combined. The annual

Correspondence to: Professor Kazushi Imai, Department of Biochemistry, School of Life Dentistry at Tokyo, The Nippon Dental University, 1-9-20 Fujimi, Chiyoda-ku, Tokyo 102-8159, Japan

E-mail: kimai@tky.ndu.ac.jp

Key words: cell proliferation, keratin, mucosa-associated lymphoid tissue 1 , oral cancer, proteomics incidence of new cases is predicted to increase in the next few decades (1). Aberrant expression of endogenous and exogenous factors cause phenotypic alterations of carcinoma cells and select aggressive clones to advanced states of carcinoma progression (2). Unveiling molecular pathways of carcinoma progression is prerequisite for the improvement of patient prognosis.

Stratified squamous epithelial cells develop keratin intermediate filaments within them. Epithelial keratins are classified into two groups according to the $\mathrm{Mr}$ and $\mathrm{pI}$; type I (K9-K28) and type II (K1-K8, K71-K80). Type I and II keratins are expressed in pairs and constitute keratin filaments in a 1:1 molar ratio. They switch the species according to a cell-type and differentiation and functional states (3). In general, keratinized squamous epithelium expresses K5 and K14 in the basal cells and K1 and K10 in the suprabasal cells. However, keratins alter their species and distribution under various pathological conditions, especially in parallel with differentiation and proliferation states of carcinoma cells (4-6). In addition, emerging evidence highlight that its alterations do not only reflect cellular conditions but also cause phenotypic changes including proliferation, apoptosis, cell growth, protein synthesis and membrane trafficking (7-11).

Our previous studies demonstrated that aggressive oral carcinomas inactivate expression of mucosa-associated lymphoid tissue 1 (MALT1) by promoter methylation, and that the patients with the loss of expression had the worst prognoses (12). MALT1 consists of three types of domains: a death domain, Ig-like domains and a caspase-like domain. $B$ cell and $T$ cell receptor antigen signals oligomerize MALT1 with BCL10 and CARMA1/3 into a CBM complex. MALT1 interacts with BCL10 through its Ig-like domains and induces I $\kappa \mathrm{B}-\mathrm{kinase}$ catalytic activity, resulting in nuclear factor- $\kappa \mathrm{B}$ $(\mathrm{NF}-\kappa \mathrm{B})$ activation $(13,14)$. In contrast to the established action in lymphocyte lineages, its role in epithelial cells and carcinoma cells is unknown. Unveiling alterations of protein expression in response to MALT1 contributes to understand the progression process. We examined the alterations by proteomic analysis and proliferation of oral carcinoma cells. 


\section{Materials and methods}

Cell lines. Oral carcinoma cell lines derived from different sites were used: oral floor, HSC2, KOSC2 and Holu1; tongue, HSC3 and OSC19; and gingiva, TSU and Ca9.22. They were obtained from the Cell Resource Center for Biomedical Research Institute of Development, Aging and Cancer (Tohoku University, Sendai, Japan) or RIKEN BRC Cell Bank (Tsukuba, Japan). Cells were cultured in RPMI-1640 or DMEM supplemented with $10 \%$ fetal bovine serum and $100 \mathrm{U} / \mathrm{ml}$ of penicillin/streptomycin (Sigma-Aldrich, St. Louis, MO). HSC2 cells, which marginally express $M A L T 1$, stably expressing full-length wild-type MALT1 (wtMALT1, wtMALT1 HSC2 cells), the $\mathrm{NH}_{2}$ terminal death and Ig-like domains-deleted dominant-negative MALTI ( $M M A L T 1,{ }_{\triangle \mathrm{MALT1}} \mathrm{HSC} 2$ cells) or vector alone ( ${ }_{\text {mock }} \mathrm{HSC} 2$ cells) were previously established (12). The wtMALT1 and $\triangle M A L T 1$ cDNA cloned into pEBMulti-Hyg with a FLAG-tag (Wako Pure Chemical Industries Ltd., Osaka, Japan) or vector alone were transiently transfected into oral carcinoma cells by electroporation. Cells were harvested $24 \mathrm{~h}$ after the transfection and used for analyses. The short interfering RNA (siRNA) targeting MALT1 (\#18601 siRNA) and a negative control siRNA (Silencer Negative Control \#1 siRNA; Ambion, Austin, TX) were used.

Protein extraction and gel electrophoresis. The ${ }_{\text {wtMALT1 } 1} \mathrm{HSC} 2$ and ${ }_{\text {mock }}$ HSC2 cells scraped from the culture dish were centrifuged at $1,500 \mathrm{rpm}$ for $7 \mathrm{~min}$ at $4^{\circ} \mathrm{C}$. The supernatant was discarded and the cell pellets were washed with ice-cold PBS three times. The pellets were solubilized in lysis buffer containing $0.1 \% \mathrm{NP}-40$ on ice and sonicated for $30 \mathrm{sec}$ three times. The lysate was centrifuged at $15,000 \mathrm{rpm}$ at $4^{\circ} \mathrm{C}$ for $15 \mathrm{~min}$ to remove insoluble materials. The resultant supernatant was collected and the protein concentration was determined by BCA protein assay (Pierce, Rockford, IL). Protein extracts $(30 \mu \mathrm{g})$ were applied to a one dimensional (1-D) SDS-PAGE gel (10\% total acrylamide) and stained with Coomassie Brilliant Blue R-250. All experiments were repeated three times from independent experiments. The gels were put on a flatbed scanner, and protein bands were compared using the Image $\mathrm{J}$ 1.46r (15). Protein bands of interest that were electrophoresed at different positions or with different intensities were subjected to MALDI-TOF mass spectrometry (MS) analysis.

In-gel digestion and MALDI-TOF MS analysis. Protein bands differentially detected between the cells were excised from the gel. The gel bands were digested by proteomics grade trypsin (Roche Diagnostics GmbH, Mannheim, Germany), and tryptic peptides were extracted from gels with $1 \%$ trifluoroacetic acid in $50 \%$ acetonitrile and dried using a vacuum pump. The digest was analyzed by MALDI-TOF MS on a Voyager DE-PRO MALDI-TOF (Applied Biosystems, Foster city, CA) with a nitrogen laser $(337 \mathrm{~nm})$. The analyte mixture $(1 \mu \mathrm{l})$ was mixed with $1 \mu \mathrm{l}$ of saturated solution of $\alpha$-cyano-4-hydroxycinnamic acid in $50 \%$ acetonitrile and $0.1 \%$ trifluoroacetic acid, and spotted on a MALDI target plate and dried at room temperature. Ion acceleration was set at $20 \mathrm{kV}$. Mass spectra were obtained by averaging 200 laser shots. Calibration of the spectra was externally calibrated with peptide mass standards (Applied Biosystems). Row data were analyzed using the computer software provided by the manufacturer as monoisotopic masses.
Average of proteins from MALDI-TOF MS spectra was achieved using the MASCOT database (MASCOT ver. 2.0, Matrix Science Inc., Boston, MA) (16). Monoisotopic peptide mass spectra were matched against the SWISS-PROT or NCBI non-redundant databases set at $\pm 1.2 \mathrm{kDa}$ peptide tolerance, limited to the Homo Sapiens proteins.

Quantitative real-time PCR. Total RNA extracted from ${ }_{\text {wtMALT1 }}$ HSC2 and ${ }_{\text {mock }}$ HSC2 cells was reverse transcribed to cDNA by MultiScribe Reverse Transcriptase (Applied Biosystems) and subjected to real-time PCR using the StepOne Real-time PCR system (Applied Biosystems). PCR conditions were $95^{\circ} \mathrm{C}$ for $20 \mathrm{sec}$ followed by 40 cycles of $95^{\circ} \mathrm{C}$ for $1 \mathrm{sec}$ and $60^{\circ} \mathrm{C}$ for $20 \mathrm{sec}$. The TaqMan probes (Applied Biosystems) specific for KRT8 (Hs01595539_g1), KRT18 (Hs02827483_g1), KRT5 (Hs00361185_m1) and KRT14 (Hs00265033_m1) were used. Expression levels $(\mathrm{n}=4)$ were normalized against $G A P D H$ (Hs02758991_m1). Levels of gene expression $\left(2^{-\Delta \Delta C t}\right)$ were determined by the standard curve method (17).

Immunoblot analysis. Total cell lysates were immunoblotted with a standard protocol. The lysates in the SDS sample buffer containing $1 \mathrm{mM}$ phenylmethanesulfonyl fluoride and protease inhibitor cocktail (Roche Diagnostics $\mathrm{GmbH}$ ) were size-fractionated by SDS-PAGE gels under reducing conditions and electrotransferred to PVDF membranes. The membrane was probed with antibodies specific to K5 (clone PRB-160P, Covance, Princeton, NJ), K8 (clone Ks 8.7, Progen Biotechnik GmbH, Heidelberg, Germany), K14 (clone LL002, Cell Marque, Rocklin, CA), K18 (clone DC 10, Dako, Glostrup, Denmark), cyclin D1 (Santa Cruz Biotechnology, Santa Cruz, CA), FLAG-M2 or $\beta$-actin (Sigma-Aldrich).

Immunostaining. Normal oral epithelium covering the oral floor and the side edge of tongue taken from patients who underwent surgery for non-tumorous diseases or positioned at the far distal site from carcinomas that were histologically considered normal by a pathologist (HY) were used for controls. All tissues were obtained with a written consent of the patient and with approval by institutional review boards of the Nippon Dental University. Unstained formalin-fixed and paraffin-embedded sections were treated with microwave $(500 \mathrm{~W})$ in $0.01 \mathrm{M}$ sodium citrate buffer, $\mathrm{pH}$ 6.0, and incubated with antibodies against K5, K8, K14 or K18 followed by biotinylated secondary antibodies (Vector Laboratories, Burlingame, CA). After treatment with avidin-biotin complexes (Vector Laboratories), the color was developed with 3,3'-diaminobenzidine tetrahydrochloride (Sigma-Aldrich).

Proliferation assay. The real-time cell electronic sensing assay based on electrical impedance readings in cell monolayers plated in wells containing built-in gold electrodes was performed. We have used the analyzer (xCELLigence RTCA-DP), 16-well E-plates and the integrated software (Roche Diagnostics GmbH). The RTCA-DP system works by measuring the electronic impedance at the cell-sensor electrode interface integrated on the bottom of E-plates. The wtMALT1 HSC2 cells, ${ }_{\triangle \mathrm{MALT1}} \mathrm{HSC} 2$ cells and ${ }_{\text {mock }} \mathrm{HSC} 2$ cells were plated at a density of $1 \times 10^{4}$ cells/well installed on the analyzer. The analyzer and the installed plates were placed in a standard 
cell culture incubator, at $37^{\circ} \mathrm{C}$ in a humidified atmosphere of $5 \%$ carbon dioxide and air. Cells were allowed to adhere to plates overnight and subjected to the analysis.

Statistical analysis. Doubling time of ${ }_{\text {wtMALT1 }} \mathrm{HSC} 2$ cells, ${ }_{\triangle \mathrm{MALT}} \mathrm{HSC} 2$ cells and ${ }_{\text {mock }}$ HSC 2 cells were statistically analyzed by Kruskal-Wallis test using JMP 7.0.1 (SAS Institute Inc., Cary, NC).

\section{Results}

Identification of proteins differentially expressed in ${ }_{\text {mock }} \mathrm{HSC} 2$ cells and ${ }_{w T M A L T 1}$ HSC 2 cells. Protein bands of ${ }_{\text {mock }}$ HSC 2 and wtMALT1 HSC2 cell lysates were compared by 1-D SDS-PAGE. Sixteen bands were differentially detected between them (9 in ${ }_{\text {mock }}$ HSC2 cells and 7 in ${ }_{\text {wtMALT1 }}$ HSC2 cells, Fig. 1), and subjected to the MALDI-TOF MS analysis. Six bands were not specified because of the non-satisfactory spectrum or the insufficient confidence of database screening to yield unambiguous results. Finally, 6 and 4 proteins were specified in ${ }_{\text {mock }} \mathrm{HSC} 2$ and ${ }_{\text {wtMALT1 }} \mathrm{HSC} 2$ cells, respectively (Table I). It includes K5 and K14 in ${ }_{\text {mock }}$ HSC2 cells and K8 and K18 in ${ }_{\text {wtMALT1 }}$ HSC2 cells. Since alterations of keratin expression associate with phenotypic changes of carcinoma cells $(5,6)$, we focused on the keratin regulation by MALT1 in this study.

Validation of keratin expression. The differential keratin expression was validated for its protein and gene expressions. K5 and K14 proteins were predominantly expressed in mock HSC2 cells and negligibly in wtMALT1 HSC2 cells (Fig. 2A). Suppression of K5 and K14 expression by MALT1 was supported by the increased expression in ${ }_{\triangle M A L T 1} H S C 2$ cells. $\mathrm{K} 8$ was not detected in mock $\mathrm{HSC} 2$ and ${ }_{\triangle \mathrm{MALT1}} \mathrm{HSC} 2$ cells but abundant in ${ }_{\text {wtMALT1 }} \mathrm{HSC} 2$ cells. K18 was also strongly detected in ${ }_{\text {wtMALT1 }}$ HSC 2 cells. The differential keratin expression was confirmed at the mRNA level (Fig. 2B). When compared to ${ }_{\text {mock }}$ HSC 2 cells, genes encoded by K5 (KRT5) and K14 (KRT14) were downregulated and upregulated in ${ }_{\text {wtMALT1 }} \mathrm{HSC} 2$ cells and ${ }_{\triangle \mathrm{MALT1}} \mathrm{HSC} 2$ cells, respectively. The ${ }_{\text {wtMALT1 }} \mathrm{HSC} 2$ cells upregulated K8 (KRT8) and K18 (KRT18) expression and ${ }_{\triangle \mathrm{MALT1}} \mathrm{HSC} 2$ cells downregulated them.

MALT1-dependency of keratin alterations. To exclude the possibility of long-term effect of MALT1 expression on the keratin expression, MALT1 cDNA was transiently transfected into the parental HSC2 cells (Fig. 3). It dose-dependently downregulated $\mathrm{K} 5$ and $\mathrm{K} 14$ and upregulated K8 and K18. Since there is a possibility that the keratin alterations are specific to HSC2 cells, we transiently transfected wtMALT1 and $\triangle M A L T 1$ cDNA in a set of oral carcinoma cells (Fig. 4). In contrast to the predominant reduction of K5 and K14 expression by wtMALT1 in most of carcinoma cells, wtMALT1 upregulated $\mathrm{K} 8 / 18$, especially in oral floor carcinoma cells.

Keratin expression in normal oral epithelium. HSC2 cells and KOSC2 cells were established from carcinomas of the non-keratinized oral floor epithelial origin $(18,19)$. Since the oral cavity is covered by non-keratinized and keratinized epithelium, keratin expression in non-keratinized oral floor and keratinized tongue epithelium were verified by the immunostaining. K8 and

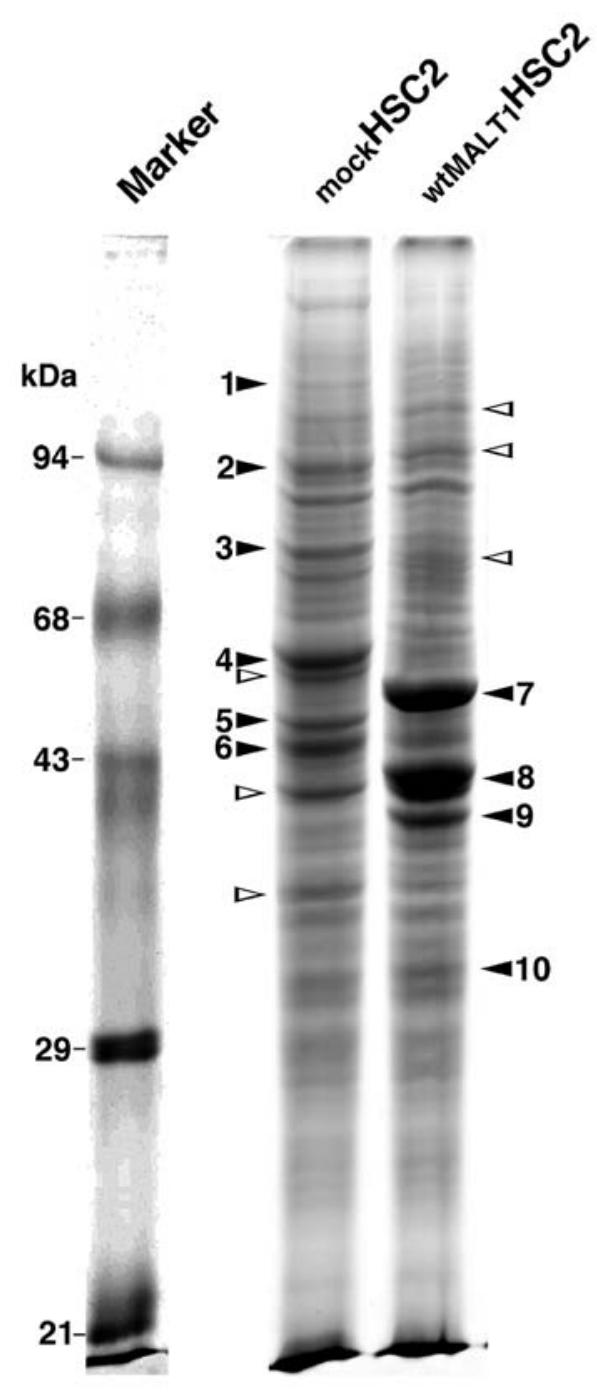

Figure 1. Protein expression in ${ }_{\text {mock }} \mathrm{HSC} 2$ cells and ${ }_{\text {wtMALT1 }} \mathrm{HSC} 2$ cells. Total cell lysates of ${ }_{\text {mock }} \mathrm{HSC} 2$ cells and ${ }_{\text {wtMALT1 }} \mathrm{HSC} 2$ cells were loaded on a 1-D SDSPAGE gel under reducing conditions. Protein bands differentially detected between the cells indicated by arrowheads were subjected to MS analysis. Numbered closed arrowheads are specified proteins and open arrowheads are unambiguous proteins. The molecular marker proteins are phosphorylase $b$ (94 kDa), bovine serum albumin (68 kDa), ovalbumin (43 kDa), carbonic anhydrase $(29 \mathrm{kDa})$ and soya-bean trypsin inhibitor $(21 \mathrm{kDa})$.

K18 were stained at the basal cells of oral floor epithelium but not the tongue epithelium, and K5 and K14 vice versa (Fig. 5). The sublingual gland staining confirmed a previous study (20); serous cells, intercalated and striated ducts were strongly positive for K8 and K18 and faintly for K5, and excretory ducts for K8, K5 and K14. Mucous cells were negative for these keratins.

Reduction of cell proliferation by MALT1. Since keratin substitution closely associates with proliferation status of squamous epithelial cells (21), effects of MALT1 on cell proliferation were examined using the real-time sensing RTCA-DP system. Fig. 6A illustrates the remarkable enhancement of ${ }_{\triangle \mathrm{MALT1}} \mathrm{HSC} 2$ cell and suppression of ${ }_{\text {wtMALT1 }} \mathrm{HSC} 2$ cell proliferation compared to the ${ }_{\text {mock }} \mathrm{HSC} 2$ cells. Doubling time of ${ }_{\text {mock }} \mathrm{HSC} 2$ cells was $11.1 \pm 0.3 \mathrm{~h}$, and ${ }_{\triangle M A L T 1} \mathrm{HSC} 2$ cells and ${ }_{\text {wtMALT1 }} \mathrm{HSC} 2$ 
Table I. Lists of identified proteins differentially expressed in ${ }_{\text {wtMALT1 }} \mathrm{HSC} 2$ and ${ }_{\text {mock }} \mathrm{HSC} 2$ cells.

\begin{tabular}{|c|c|c|c|c|c|c|c|}
\hline \multirow[b]{2}{*}{ Protein no. } & \multirow[b]{2}{*}{ Accession no. ${ }^{a}$} & \multirow[b]{2}{*}{ Annotation } & \multicolumn{2}{|c|}{$\mathrm{Mr}(\mathrm{kDa})$} & \multirow[b]{2}{*}{ Coverage $(\%)^{\mathrm{d}}$} & \multirow[b]{2}{*}{ MS score ${ }^{\mathrm{e}}$} & \multirow[b]{2}{*}{ Authors/(Refs.) } \\
\hline & & & Theor. ${ }^{b}$ & Obs..$^{c}$ & & & \\
\hline \multicolumn{8}{|c|}{ mock $\mathrm{HSC} 2$ cells } \\
\hline 1 & Q8N1G0 & $\begin{array}{l}\text { Zinc finger } \\
\text { protein } 687\end{array}$ & 115.6 & 129.5 & 16 & 27 & $\begin{array}{l}\text { Malovannaya } \\
\text { et al (38) }\end{array}$ \\
\hline 2 & Q8NB90 & $\begin{array}{l}\text { Spermatogenesis } \\
\text { associated } 5\end{array}$ & 97.7 & 97.9 & 25 & 32 & Heallen et al (39) \\
\hline 3 & P11021 & GRP78 precursor & 72.1 & 72.3 & 38 & 85 & Dong et al (40) \\
\hline 4 & P13647 & Keratin 5 & 62.4 & 62.4 & 27 & 64 & \\
\hline 5 & P02533 & Keratin 14 & 44.7 & 51.6 & 23 & 38 & \\
\hline 6 & 43502 & RAD51 homolog C & 42.6 & 42.2 & 23 & 47 & Clague et al (41) \\
\hline \multicolumn{8}{|c|}{ wtMALT1 HSC2 cells } \\
\hline 7 & Q6GMYO & Keratin 8 & 53.4 & 53.7 & 34 & 61 & \\
\hline 8 & PO5783 & Keratin 18 & 47.3 & 48.1 & 38 & 52 & \\
\hline 9 & P38159 & $\begin{array}{l}\text { RNA-binding } \\
\text { motif protein }\end{array}$ & 42.3 & 44.3 & 43 & 40 & Tsuei et al (42) \\
\hline 10 & Q02978 & $\begin{array}{l}\text { Solute carrier } \\
\text { family } 25\end{array}$ & 34.1 & 34.1 & 26 & 28 & Zhong et al (43) \\
\hline
\end{tabular}

${ }^{a}$ Uniprot (www.uniprot.org) accession number. ${ }^{\mathrm{b}}$ Theoretical $\mathrm{Mr}(\mathrm{kDa}) .{ }^{\mathrm{c}}$ Observed $\mathrm{Mr}(\mathrm{kDa})$ in 1-D SDS-PAGE. ${ }^{\mathrm{d} N u m b e r}$ of sequence coverage in MALDI-TOF MS. ${ }^{\mathrm{e} M A S C O T}$ score. ${ }^{\mathrm{f}}$ References except for keratins.

A

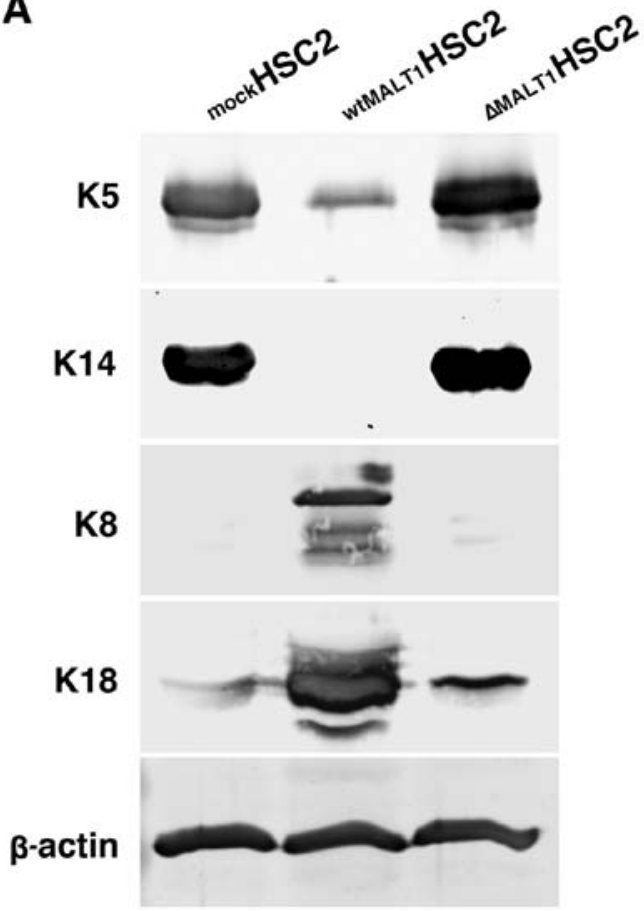

B

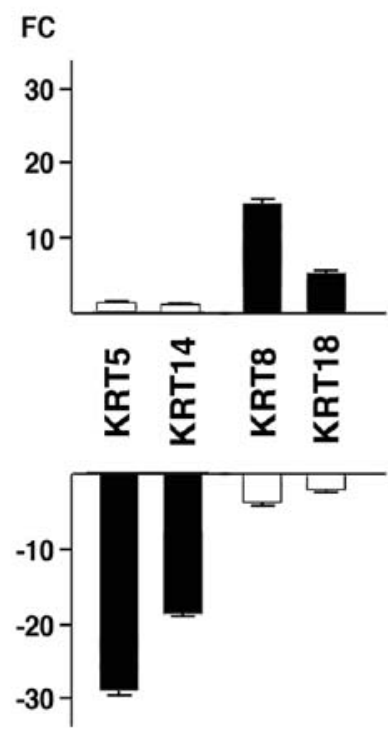

Figure 2. Validation of keratin expression in HSC2 cells. (A) Expression of K5, K14, K8 and K18 in ${ }_{\text {mock }}$ HSC2 cells, ${ }_{\text {wtMALT1 }} \mathrm{HSC} 2$ cells and ${ }_{\Delta \mathrm{MALT1}} \mathrm{HSC} 2$ cells were validated by immunoblotting. $\beta$-actin was used for an internal control. (B) Relative fold of expression of genes encoding K5 (KRT5), K14 (KRT14), K8 (KRT8) and K18 (KRT18) in wtMALT1 HSC2 cells (closed bars) and ${ }_{\triangle M A L T 1}$ HSC2 cells (open bars) were compared with mock HSC2 cells by quantitative real-time PCR (n=4). The expression was standardized by expression level of GAPDH in each sample.

were $8.4 \pm 0.5$ and $21.3 \pm 2.1 \mathrm{~h}$, respectively $(\mathrm{P}<0.01)$. Decreased proliferation of ${ }_{\text {wtMALT1 }} \mathrm{HSC} 2$ cells was not due to the cell death because they did not increase the TUNEL reactivity (Fig. 6B) and the trypan blue staining (data not shown). The ${ }_{\text {wtMALT1 }}$ HSC2 cells ceased cyclin D1 expression but restored it by the siRNA against MALT1 in a dose-dependent manner (Fig. 6C and D). 
HSC2

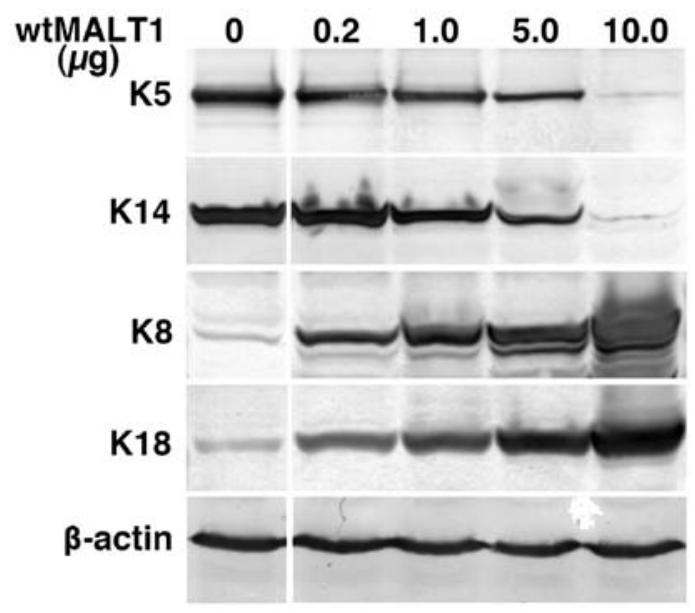

Figure 3. Dose-dependent expression of keratins. HSC2 cells transiently transfected with different doses of wtMALT1 cDNA were examined for keratin expression by immunoblot analysis. $\beta$-actin was used for an internal control.

The ${ }_{\triangle M A L T 1} \mathrm{HSC} 2$ cells and ${ }_{\text {mock }} \mathrm{HSC} 2$ cells did not respond to the siRNA because of the lack of siRNA-binding site in a $\triangle M A L T 1$ gene construct and the marginal expression of endogenous $M A L T 1$, respectively.

\section{Discussion}

MALT1 is expressed in normal epithelial cells of the oral cavity and the loss of expression closely associates with carcinoma progression in an unknown mechanism (12). Identifying protein expression and cellular phenotype under the control of MALT1 contributes to the understanding of its role. We report that the loss of expression stimulates K5/14 expression and proliferation of oral carcinoma cells and decreases K8/18 expression.

We analyzed proteins that were differentially expressed in wtMALT1 $\mathrm{HSC} 2$ cells and ${ }_{\text {mock }} \mathrm{HSC} 2$ cells by the MS analysis, and detected keratins and other proteins involved in gene transcription, and proliferation, chemo-resistance and development of tumors (Table I). It is noteworthy that 4 different keratins were included. Since K8/18 and K5/14 are primary pairs, it is reasonable to hypothesize that MALT1 affects keratin filament organization. Although K8 and K18 are known as simple epithelial keratins and not expressed in keratinized epithelium (3), non-keratinized squamous epithelium of the esophagus expresses them in the basal cells (22). Oral floor epithelium shares its histological characteristics with the esophagus (23). Keratin expression in non-keratinized oral floor epithelium is largely different from that in keratinized oral epithelium (24), and HSC2 cells were established from an oral floor carcinoma (18). K8/18 and K5/14 expression and localization in oral floor epithelium has not been clearly documented, and K5 and K14 expression in non-keratinized epithelium is a controversial issue. We immunostained them in oral floor epithelium and tongue epithelium that is juxtaposed to oral floor. K8 and K18 were positively stained in the basal cells of oral floor epithelium and $\mathrm{K} 5$ and $\mathrm{K} 14$ at that of tongue epithelium. The staining patterns in the sublingual gland strictly confirmed a previous study (20), indicating specific reactions of the staining. These data show that $\mathrm{K} 8 / 18$ and $\mathrm{K} 5 / 14$ expression in non-keratinized and keratinized oral epithelium are largely different.

K5 and K14 reduction was a MALT1 dose-dependent in HSC 2 cells and observed in most of the carcinoma cell lines, indicating that K5 and K14 repression by MALT1 is a prevalent feature in oral carcinoma cells. They are expressed in mitotically active basal cells of oral epithelium (4), upregulated in oral carcinomas (25), and downregulated upon differentiation of carcinoma cells (21). The K14 knockdown initiates epithelial differentiation marker expression including involcurin and $\mathrm{K} 1$ and suppresses carcinoma cell proliferation and tumorigenicity (21). We previously showed that MALT1 upregulates involcurin and $\mathrm{K} 10$, a primary partner of $\mathrm{K} 1$, and downregulates vimentin, a mesenchymal cell-type intermediate filament (12). The present study demonstrated the reduction of proliferation by MALT1; 1.92-fold increase and 1.33-fold decrease of doubling time of ${ }_{\text {wtMALT1 }} \mathrm{HSC} 2$ cells and ${ }_{\triangle \mathrm{MALT1}} \mathrm{HSC} 2$ cells, respectively. Decreased proliferation of ${ }_{\text {wtMALT1 }} \mathrm{HSC} 2$ cells associated with the dramatic reduction of cyclin D1 expression that was recovered by transfection of MALT1-siRNA in a dose-dependent manner. These facts underscore an involvement of loss of MALT1 expression in K5 and K14 upregulation that stimulates de-differentiation and proliferation of oral carcinoma cells.

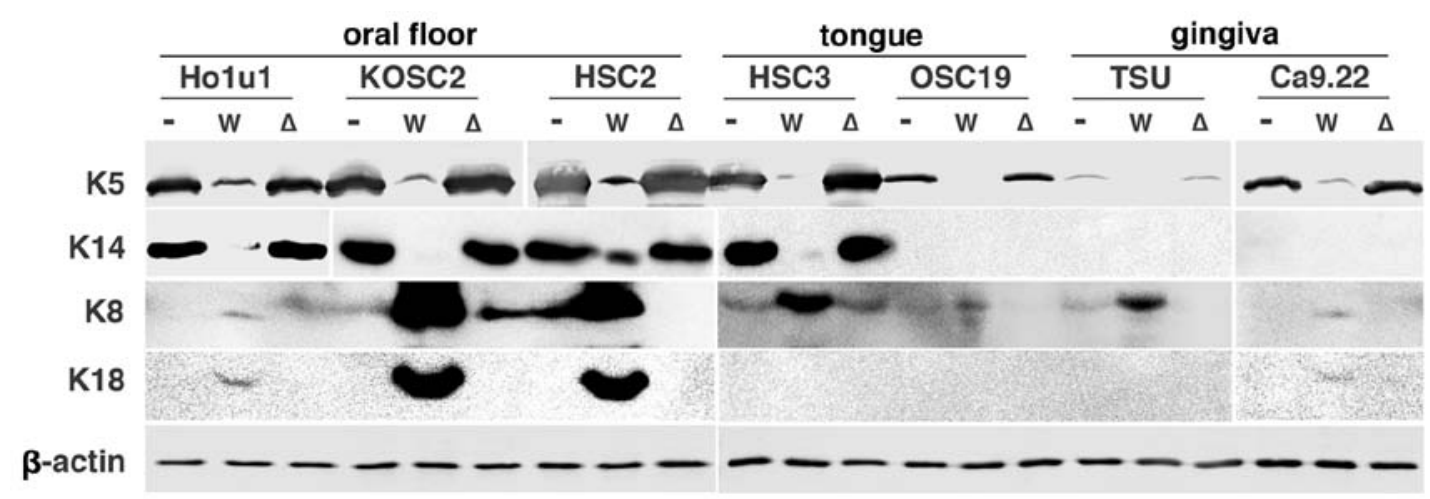

Figure 4. Effect of MALT1 on keratin expression in various oral carcinoma cells. Seven different oral carcinoma cell lines were transiently transfected vector alone (-), $\triangle M A L T 1(\Delta)$ or wtMALT1 cDNA (w, $10 \mu \mathrm{g})$ and subjected to immunoblotting for K5, K14, K8 and K18. $\beta$-actin was used for an internal control. 
A

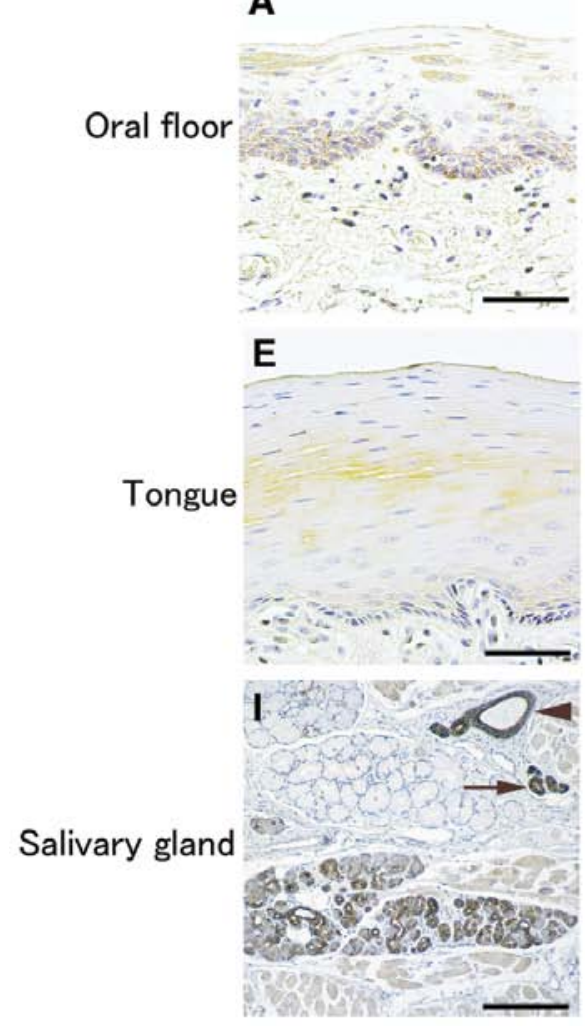

B

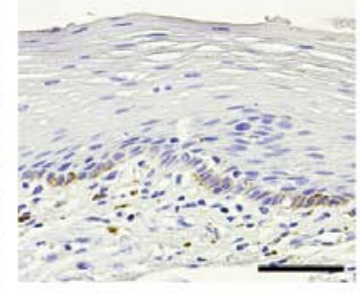

F
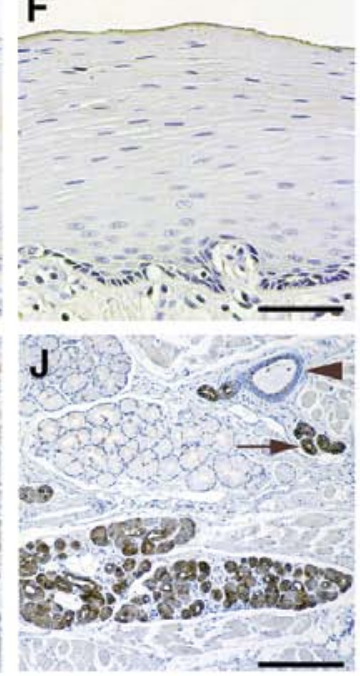

C

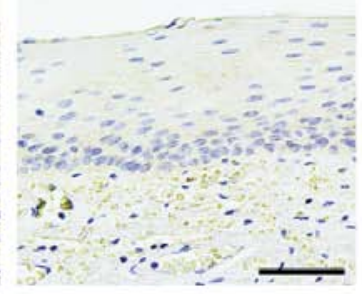

\section{G}

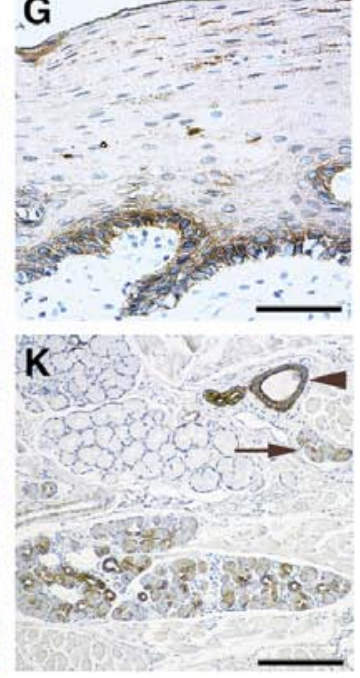

D
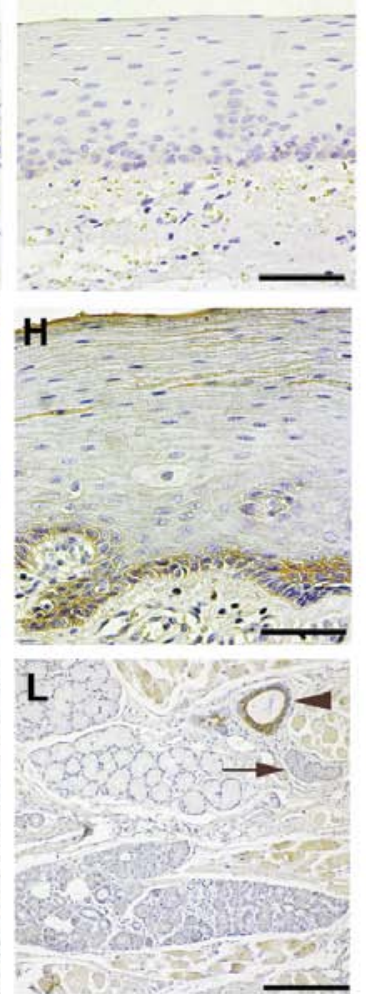

Figure 5. Expression of keratins in normal oral floor and gingival epithelium. Oral epithelium covering the oral floor (non-keratinized epithelium), the tongue edge (keratinized epithelium) and sublingual gland were immunostained for K8 (A, E, I), K18 (B, F, J), K5 (C, G, K) and K14 (D, H, L). K8 and K18 were localized at basal cells of oral floor and K5 and K14 at that of tongue. In the sublingual gland, keratin localization confirmed a previous study (Azevedo et al 20). Arrows and arrowheads point to excretory ducts and striated ducts, respectively. Bar, $35 \mu \mathrm{m}(\mathrm{A}-\mathrm{H})$ and $70 \mu \mathrm{m}(\mathrm{I}-\mathrm{L})$.

A

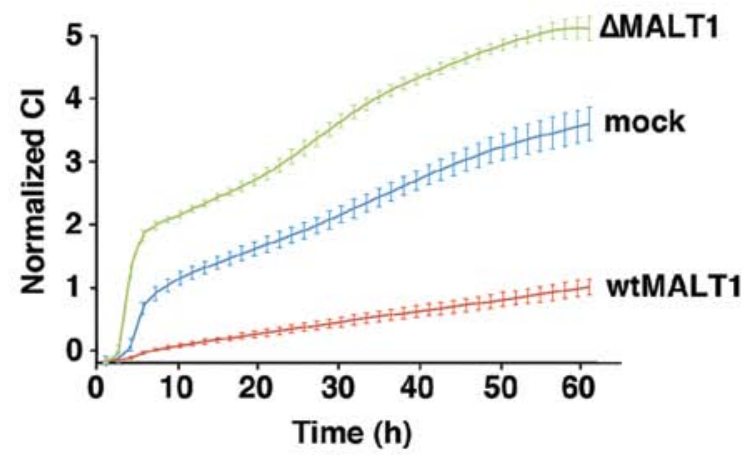

C

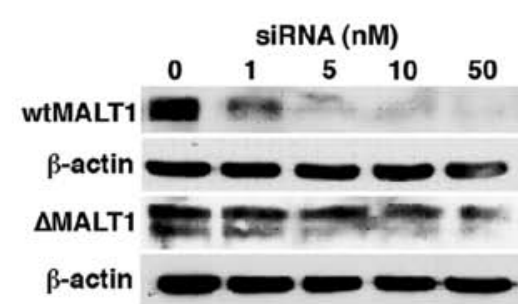

B

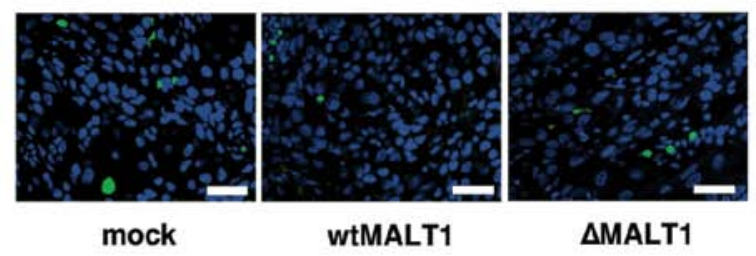

D

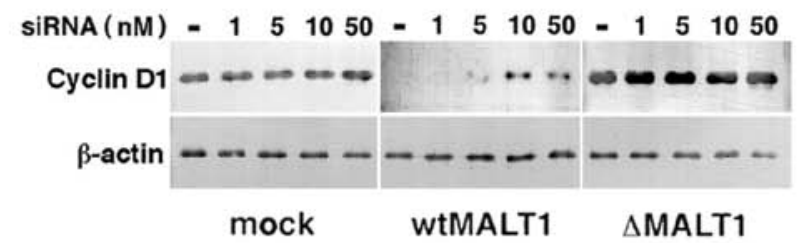

Figure 6. Proliferation of HSC2 cells stably expressing the MALT1 constructs. (A) Real-time monitoring of proliferation of ${ }_{\text {mock }} \mathrm{HSC} 2$ cells, wimaLT1 $\mathrm{HSC} 2$ cells and ${ }_{\triangle M A L T 1}$ HSC2 cells. Normalized cell index (CI) indicated electrical impedance readings between E-plates and attached cells. Mean value for each cell ( $\mathrm{n}=5$ ) is presented as SD at every $10 \mathrm{~min}$. (B) Apoptosis analysis of ${ }_{\text {mock }} \mathrm{HSC} 2$ cells, ${ }_{\text {wMALT1 }} \mathrm{HSC} 2$ cells and ${ }_{\triangle M A L T 1} \mathrm{HSC} 2$ cells by TUNEL assay. (C) Knockdown of MALT1 protein expression in ${ }_{\text {wIMALT1 }} \mathrm{HSC} 2$ cells and ${ }_{\triangle M A L T 1} \mathrm{HSC} 2$ cells by the siRNA. The $w t M A L T 1$ and $\triangle M A L T 1$ protein expression was probed by immunoblot analysis with an anti-FLAG antibody. $\beta$-catenin is shown as the internal control. (D) Cyclin D1 expression in ${ }_{\text {mock }} \mathrm{HSC} 2$ cells, wtMALT1 HSC2 cells and ${ }_{\triangle M A L T 1} \mathrm{HSC} 2$ cells. Cyclin D1 in response to MALT1 siRNA dose-dependency was analyzed by immunoblotting. $\beta$-actin indicates an internal control. 
MALT1 strongly upregulated K8 and K18 in oral floor carcinoma cells and faintly in keratinized oral epithelium-derived carcinoma cells. Forced expression of K18 in breast carcinoma cells, which are originated from the most representative K8/18-positive simple epithelial cells, reduces proliferation and aggressive behavior of carcinoma cells in vitro and in mice $(11,26,27)$. Reduction of K8/18 expression actively renders the aggressive properties to carcinoma cells (11). Although the pathological contribution of $\mathrm{K} 8 / 18$ to oral carcinomas is controversial $(28,29)$, this study demonstrated the $\mathrm{K} 8 / 18$ upregulation and the K5/14 downregulation by MALT1 that is expressed at the early stage of carcinomas and inactivated at the late stage (12).

K5/14-positive breast carcinomas exhibit worse pathological grades, and patient survival than the K8/18-positive carcinomas (30). Expression of $\mathrm{K} 5 / 14$ is an independent risk factor for worse prognosis of oral carcinomas (31). Although a molecular mechanism for MALT1-dependent keratin alteration is uncertain, our recent microarray analysis indicated that MALT1 preferentially downregulates EGF and TGF- $\beta$ pathway gene expression (32). EGF and TGF- $\beta$ signaling suppress K8/18 expression and stimulate K5/14 expression, provoking proliferative and aggressive behavior of carcinoma cells (33-37). Loss of MALT1 expression initiates the K8/18-to-K5/14 alteration with enhanced proliferation and may prompt aggressive behavior of oral carcinomas toward worse prognosis. Future studies on the molecular action of MALT1 is required to extend the understanding of pathophysiology of oral carcinoma progression.

\section{Acknowledgements}

This study was supported by a grant from the Institutional Research Projects of the Nippon Dental University (2010-3) and by grants from JSPS KAKENHI (22592080 and 22592103). This study is based on a thesis submitted to Graduate School of Dentistry, Meikai University, in partial fulfillment of the requirements for the Doctor of Dental Surgery degree.

\section{References}

1. Choi S and Myers JN: Molecular pathogenesis of oral squamous cell carcinoma: implications for therapy. J Dent Res 87: 14-32, 2008.

2. Hanahan D and Weinberg RA: Hallmarks of cancer: the next generation. Cell 144: 646-674, 2011.

3. Schweizer J, Bowden PE, Coulombe PA, Langbein L, Lane EB, Magin TM, Taltais L, Omary MB, Parry DA, Rogers MA and Wright MW: New consensus nomenclature for mammalian keratins. J Cell Biol 174: 169-174, 2006.

4. Bosh FX, Ouhayoun JP, Bader BL, Collin C, Grund C, Lee I and Franke WW: Extensive changes in cytokeratin expression patterns in pathologically affected human gingiva. Virchows Archiv B Cell Pathol 58: 59-77, 1989.

5. Karantza V: Keratins in health and cancer: more than mere epithelial markers. Oncogene 30: 127-138, 2011.

6. Kurokawa I, Takahashi K, Moll I and Moll R: Expression of keratins in cutaneous epithelial tumors and related disorders - distribution and clinical significance. Exp Dermatol 20: 217-228, 2011.

7. Coulombe PA and Omary MB: 'Hand' and 'soft' principles defining the structure, function and regulation of keratin intermediate filaments. Curr Opin Cell Biol 14: 110-122, 2002.

8. Oshima RG: Apoptosis and keratin intermediate filaments. Cell Death Differ 9: 486-492, 2002.

9. Pan X, Hobbs RP and Coulombe PA: The expanding significance of keratin intermediate filaments in normal and disease epithelia. Curr Opin Cell Biol 25: 47-56, 2013.
10. Kim S, Wong P and Coulombe PA: A cytoskeletal protein regulates protein synthesis and epithelial cell growth. Nature 441: 362-365, 2006.

11. Fortier AM, Asselin E and Cardin M: Keratin 8 and 18 loss in epithelial cancer cells increases collective cell migration and cispatin sensitivity through claudin 1 up-regulation. J Biol Chem 288: 11555-11571, 2013.

12. Chiba T, Maeda G, Kawashiri S, Kato K and Imai K: Epigenetic loss of mucosa-associated lymphoid tissue 1 expression in patients with oral carcinomas. Cancer Res 69: 7216-7223, 2009.

13. Thome M: Multifunctional roles of MALT1 in T-cell activation. Nat Rev Immunol 8: 495-500, 2008.

14. McAllister-Lucas LM, Baens M and Lucas PC: MALT1 protease: a new therapeutic target in B lymphoma. Clin Cancer Res 17: 6623-6631, 2011.

15. Schneider CA, Rasband WS and Eliceiri KW: NIH Image to ImageJ: 25 years of image analysis. Nat Methods 9: 671-675, 2012.

16. Perkins DN, Pappin DJC, Creasy DM and Cottrell JS: Probability-based protein identification by searching sequence databases using mass spectrometry data. Electrophoresis 20: 3351-3367, 1999 .

17. Schmittgen DD and Livak KJ: Analyzing real-time PCR data by the comparative CT method. Nat Protoc 3: 1101-1108, 2008.

18. Momose F, Araida T, Negishi A, Ichijo H, Shioda S and Sasaki S: Variant sublines with different metastatic potentials selected in nude mice from human oral squamous cell carcinomas. J Oral Pathol Med 18: 391-395, 1989.

19. Inagaki T, Matsuwari S, Takahashi R, Shimada K, Fujie K and Maeda S: Establishment of human oral-cancer cell lines (KOSC-2 and -3) carrying p53 and c-myc abnormalities by geneticin treatment. Int J Cancer 56: 301-308, 1994.

20. Azevedo RS, De Almeida OP, Kowalski LP and Pires FR Comparative cytokeratin expression in the different cell types of salivary gland mucoepidermoid carcinoma. Head Neck Pathol 2: 257-264, 2008.

21. Alam H, SehgalL, Kundu ST, Dalal S and Vaidya MM: Novel function of keratins 5 and 14 in proliferation and differentiation of stratified epithelial cells. Mol Biol Cell 22: 4068-4078, 2011.

22. Bosh FX, Leube RE, Achtstätter T, Moll R and Franke WW: Expression of simple epithelial type cytokeratins in stratified epithelia as detected by immunolocalization and hybridization in situ. J Cell Biol 106: 1635-1648, 1998.

23. Squier CA and Kremer MJ: Biology of oral mucosa and esophagus. J Natl Cancer Inst Monogr 29: 7-15, 2001.

24. Clausen H, Moe D, Buschard K and Dabelsteen E: Keratin proteins in human oral mucosa. J Oral Pathol 15: 36-42, 1986.

25. Thiel UJE, Feltens R, Adryan B, Gieringer R, Brochhausen C, Schyon R, Fillies T, Grus F, Mann WJ and Brieger J: Analysis of differentially expressed proteins in oral squamous cell carcinoma by MALDI-TOF MS. J Oral Pahtol Med 40: 369-379, 2011.

26. Iyer SV, Dange PP, Alam H, Sawant SS, Ingle AD, Borges AM, Shirsat NV, Dalal SN and Vaidya MM: Understanding the role of keratins 8 and 18 in neoplastic potential of breast cancer derived cell lines. PLoS One 8: e53532, 2013.

27. Buhler H and Schaller G: Transfection of keratin 18 gene in human breast cancer cells causes induction of adherent proteins and dramatic regression of malignancy in vitro and in vivo. Mol Cancer Res 3: 365-371, 2005.

28. Matthias C, Mack B, Berghaus A and Gires O: Keratin 8 expression in head and neck epithelia. BMC Cancer 8: 267, 2008.

29. Imai K, Kumagai S, Nakagawa K, Yamamoto E, Nakanishi I and Okada Y: Immunolocalization of desmoglein and intermediate filaments in human oral squamous cell carcinomas. Head Neck 17: 204-212, 1995.

30. Abd El-Rehim DM, Pinder SE, Paish CE, Bell J, Blamey RW, Robertson JFR, Nicholson R and Ellis IO: Expression of luminal and basal cytokeratins in human breast carcinoma. J Pathol 203: 661-671, 2004.

31. Garrel R, Dromard M, Costes V, Barbotte E, Comte F, Gardiner Q, Cartier C, Makeieff M, Crampette L, Guerrier B and Boulle N: The diagnostic accuracy of reverse-transcription PCR quantification of cytokeratin mRNA in sentinel lymph node invasion in oral and oropharyngeal squamous cell carcinoma: a comparison with immunohistochemistry. Clin Cancer Res 12: 2498-2505, 2006.

32. Ohyama Y, KawamotoY, Chiba T, Yagishita H, Sakashita H and Imai K: Inhibition of TGF- $\beta$ and EGF pathway gene expression and migration of oral carcinoma cells by mucosa-associated lymphoid tissue 1. BrJ Cancer (In press). 
33. Zeineldin R, Rosenberg M, Ortega D, Buhr C, Chavez MG, Stack MS, Kusewitt DF and Hudson LG: Mesenchymal transformation in epithelial ovarian tumor cells expressing epidermal growth factor receptor variant III. Mol Carcinog 45: 851-860, 2006.

34. Kinouchi M, Takahashi H, Itoh Y, Ishida-Yamamoto A and Iizuka H: Ultraviolet B irradiation increase keratin 5 and keratin 14 expression through epidermal growth factor receptor of SV40-transformed human keratinocytes. Arch Dermatol Res 293: 634-641, 2002.

35. Jiang CK, Tomic-Canic $M$, Lucas DJ, Simon $M$ and Blumenberg M: TGF beta promotes the basal phenotype of epidermal keratinocytes: transcriptional induction of K\#5 and K\#14 keratin gene. Growth Factor 12: 87-97, 1995.

36. Shukla A, Ho Y, Liu X, Ryscavage A and Glick AB: Cripto-1 alters keratinocyte differentiation via blockade of transforming growth factor-beta 1 signaling: role in skin carcinogenesis. Mol Cancer Res 6: 509-516, 2008

37. Zhang Q, Helfand BT, Jang TL, Zhu LJ, Chen L, Yang XJ, Kozlowski J, Smith N, Kundu SD, Yang G, Raji AA, Javonovic B, Pins M, Lindholm P, Guo Y, Catalona WJ and Lee C: Nuclear factor- $\kappa \mathrm{B}$-mediated transforming growth factor- $\beta$-induced expression of vimentin is an independent predictor of biochemical recurrence after radical prostatectomy. Clin Cancer Res 15: 3557-3567, 2009.

38. Malovannaya A, Lanz RB, Jung SY, Bulynko Y, Le NT, Chan DW, Ding C, Yucer N, Krenciute G, Kim BJ, Li C, Chen R, Li W, Wang Y, O'Malley BW and Qin J: Analysis of the human endogenous coregulator complexome. Cell 145: 787-799, 2011.
39. Heallen TR, Adams HP, Furuta T, Verbrugghe KJ and Schumacer JM: An Afg2/Spaf-related Cdc48-like AAA ATPase regulates the stability and activity of the c. elegans Aurora B kinase AIR-2. Dev Cell 15: 603-616, 2008.

40. Dong D, Stapleton C, Luo B, Xiong S, Ye W, Zhang Y, Jhaveri N, Zhu G, Ye R, Liu Z, Bruhn KW, Craft N, Groshen S, Hofman FM and Lee AS: A critical role of GRP78/BiP in the tumor microenvironment for neovascularization during tumor growth and metastasis. Cancer Res 71: 2848-2857, 2011.

41. Clague J, Wilhoite G, Adamson A, Bailis A, Weitzel JN and Neuhausen SL: RAD51C germline mutations in breast and ovarian cancer cases from high-risk families. PLoS ONE 6: e25632, 2011

42. Tsuei DJ, Hsu HC, Lee PH, Jeng YM, Pu YS, Chen CN, Lee YC, Chou WC, Chang CJ, Ni YH and Chang JMH: RBMY, a male germ cell-specific RNA-binding protein, activated in human liver cancers and transforms rodent fibroblasts. Oncogene 23: 5815-5822, 2004

43. Zhong Q, Putt DA, Xu F and Lash LH: Hepatic mitochondrial transport of gluthathione: studies in isolated rat liver mitochondria and H4IIE rat hepatoma cells. Arch Biochem Biophys 474: $119-127,2008$. 